\title{
A physical modeling approach for identification of source regions of primary and secondary air pollutants
}

\author{
J. C. F. Lo ${ }^{1}$, A. K. H. Lau ${ }^{2,3}$, Z. B. Yuan ${ }^{1}$, J. C. H. Fung ${ }^{3}$, and F. Chen ${ }^{4}$ \\ ${ }^{1}$ Atmospheric, Marine and Coastal Environment Program, The Hong Kong University of \\ Science and Technology, Hong Kong, P. R. China \\ ${ }^{2}$ Environmental Central Facility, Institute for the Environment, The Hong Kong University of \\ Science and Technology, Hong Kong, P. R. China \\ ${ }^{3}$ Department of Mathematics, The Hong Kong University of Science and Technology, Hong \\ Kong, P. R. China \\ ${ }^{4}$ National Center for Atmospheric Research, Boulder, Colorado, USA \\ Received: 3 March 2006 - Accepted: 15 May 2006 - Published: 13 July 2006 \\ Correspondence to: J. C. F. Lo (jeffcf_lo@mail.utexas.edu)
}

6467

\begin{abstract}
This paper describes a simple but practical methodology to identify the contribution of primary and secondary air pollutants from the local/regional emission sources to Hong Kong, a highly urbanized city with complex terrain and coastlines. The meteo5 rological model MM5 coupled with a three-dimensional, mutli-particle trajectory model is used to identify salient aspects of regional air pollutant transport characteristics during some typical meteorological conditions over the Pearl River Delta (PRD) region. Several weighting factors are determined for calculating the air mass/pollutant trajectory and are used to evaluate the local and regional contribution of primary pollutants

10 over the PRD to Hong Kong pollution. The relationships between emission inventories, physical paths and chemical transformation rates of the pollutants, and observational measurements are formulated. The local and regional contributions of secondary pollutants are obtained by this conceptual module under different weather scenarios. Our results demonstrate that major pollution sources over Hong Kong come from regional

15 transport. In calm-weather situations, $78 \%$ of the respirable suspended particulates (RSP) totals in Hong Kong are contributed by regional transport, and $49 \%$ are contributed by the power plants within the PRD. In normal-day situations, $71 \%$ of the RSP are contributed by regional transport, and $45 \%$ are contributed by the power plants.
\end{abstract}

\section{Introduction}

20 Hong Kong, located in the southeast part of Pearl River Delta (PRD) region, is a mega city of $1100 \mathrm{~km}^{2}$ area containing 7 million people. In the past decades, both Hong Kong and the PRD have seen significant economic and population growth, but unfortunately, this growth is accompanied by deteriorated air quality within the entire PRD region. According to the annual report of Hong Kong Environment Protection Department (HKEPD, 2003), street-level pollution and smog are the two major pollution problems in Hong Kong. The poor air quality in street level is primarily caused by the high 
volume of local traffics. While the regional smog problems, such as the poor visibility, high levels of respirable suspended particulates (RSP) and ozone $\left(\mathrm{O}_{3}\right)$ episodes, are caused not only by the emissions from the motor vehicles, but also by emissions from the industry and power plants both within Hong Kong and in the PRD (HKEPD, 2003).

Under a series of stringent air quality control implemented by the Hong Kong government, such as cutting sulphur content of industrial fuels and ameliorating motor vehicle fuel quality, emissions from local industry and automobile have been reducing in the recent decade. According to HKEPD (2003), emissions of particulate matters (PM), sulfur dioxide $\left(\mathrm{SO}_{2}\right)$, and nitrogen oxide $\left(\mathrm{NO}_{\mathrm{x}}\right)$ in 2003 dropped by $50 \%, 54 \%$

10 and $41 \%$ respectively, compared with their levels in 1993 . However, the $\mathrm{O}_{3}$ level in Hong Kong, as evidenced by the duration of poor visibility and frequency of occurrence of $\mathrm{O}_{3}$ episodes, has been in an increasing trend in the recent years (HKEPD, 2003). The percentage of dates with poor visibility (visibility less than $8 \mathrm{~km}$ with relative humidity recorded less than $80 \%$ ) in $2003(15 \%)$, was 2.5 times the 1993 value (6\%).

15 Since $\mathrm{O}_{3}$ and smog problem is a regional air pollution issue, the rising trend generally reflects deterioration in air quality on a regional scale over the past decade. A question has been raised as to whether local emission sources or pollutants transported from outside Hong Kong are responsible for this air quality impairment.

As air pollution is a trans-boundary issue, certain air pollutants can be transported 20 for long distances and impact the locations far from the sources. It is sometimes difficult to identify the source regions of air pollutants which contributing to the pollution episodes. In previous air quality studies, simple air mass trajectory analysis, which trace air parcels forward or backward in time from the receptor, was generally used to identify source regions of air pollutants (e.g. Harris et al., 1994; Chan et al., 2001; Oltmans et al., 2004). However, this method usually only involves physical advection calculations, and it cannot compute or categorize the contributions of specific pollutants. What make things futher complicated is the transformation of gaseous pollutant into particle phase. Certain types of pollutants, such as nitric acid, tend to coagulate onto existing particles and form particulate nitrate under conditions of high relative humidity

6469

and low temperature (Stelson and Seinfeld, 1982). In addition, Yuan et al. (2006a) estimated that secondary aerosol accounted for an annual average of $44 \%$ of $\mathrm{PM}_{10}$ in Hong Kong. Therefore, formation of secondary particles should not be neglected for any PM study in Hong Kong and the PRD region. A chemical module must be 5 incorporated to estimate the formation of secondary aerosol in the air.

The purpose of this paper is to introduce a simple and particle methodology which based on trajectory calculations for identification of source regions of air pollutants. The advanced meteorological model MM5 coupled with a three-dimensional, multi-particle trajectory (MPT) model is used to identify salient aspects of regional air pollutant trans10 port characteristics during two typical meteorological conditions over the PRD: 1) calmweather days with stationary synoptic-scale forcing. 2) typical-wind situations with most frequently occurrence wind profiles. Pollutant trajectory in the MPT model is simulated by tracking a large set of particles. The MPT model is superior to standard singleparticle trajectory model because it can better take into account the substantial local variability of the wind field, and hence provides a better description of the overall behavior of the air pollutants. Several weighting factor tables are established to the particle trajectory calculations and are used to evaluate local and regional contribution of primary pollutants over the PRD to Hong Kong pollution. In addition, a conceptual module formulating the relationships between emission inventories, physical paths and chem20 ical transformation rates of the pollutants, and observational measurements, is developed. The conceptual conversion rates of primary gas phase pollutants to secondary PM (e.g. $\mathrm{SO}_{2}$ to sulfate and $\mathrm{NO}_{\mathrm{x}}$ to nitrate) are obtained by the conceptual module. These conversion rates provide the information of local and regional secondary pollutants in Hong Kong. The differences of pollutant transport characteristics over western 25 and eastern Hong Kong have also been investigated. 


\section{Methodology}

\subsection{Meteorological model and configuration}

The meteorological model used in this study is the Pennsylvania State University (PSU)/National Center for Atmospheric Research (NCAR) Fifth-Generation Mesoscale

5 Model (MM5) version 3.6.3, configured with the physical parameterization schemes summarized in Table 1. A 1-km-fine-resolution (mesh size, 300×300) domain covering Hong Kong and PRD (Fig. 1) is used to resolve local and regional scale atmospheric circulations features.

The simple microphysical parameterization for cloud water, rain water and ice (Dud-

10 hia, 1993) and explicit convection are applied in the simulation domain. Short-wave radiation processes are handled using a cloud radiation scheme (Grell et al., 1994), and a Rapid Radiative Transfer Model (RRTM) (Mlawer et al., 1997) is applied for long-wave radiation processes. National Centers for Environment Prediction (NCEP)'s Medium-Range Forecast scheme (MRF) PBL scheme (Hong and Pan, 1996) is used

15 in this study. The Noah land surface model (Noah LSM) with a bulk urban land-use treatment is used for the land surface scheme (Chen and Dudhia, 2001; Liu et al., 2006). These physical parameterizations and urban land-use enhancements demonstrated the capability to capture major features of the observed urban heat island (UHI) effect and sea breeze circulation (SBC) patterns in the PRD region (Lo, 2006).

20 In order to investigate the typical features of the local and regional scale atmospheric circulations and isolate these conditions from the other complexities of the real atmosphere, idealized meteorological initial and boundary conditions are ingested to the MM5 simulations. The pollutant transport characteristics over PRD under two distinct meteorological conditions are examined. The first one represents an extreme situation

25 of total stationary synoptic weather, with no horizontal pressure gradient and no background winds in the MM5 initial and boundary conditions, i.e. circulations over PRD are solely driven by the local thermal effects, including the land-sea temperature contrast as well as the $\mathrm{UHI}$ effect. The second one represents a typical wind situation 6471

with $6 \mathrm{~m} \mathrm{~s}^{-1}$ north-easterly wind at the surface. Detailed discussions of the idealized meteorological conditions setup can be found in Lo (2006). A 30-h simulation is conducted by MM5, with the first six hours used as the spin-up, and the rest $24 \mathrm{~h}$ as the effective simulation in order to capture the daily diurnal feature of the thermally induced 5 circulation systems over PRD, including the land-sea breeze (LSB) and UHI circulation.

\subsection{Multi-Particle Trajectory (MPT) model}

In addition to the MM5 model, a multi-particle trajectory model (MPT) is also coupled with the meteorological model to help illustrate the air-flow pattern and the associated dispersion driven by the local atmospheric circulations. The prognostic model MM5

10 is used to predict meteorological conditions. The MPT model is subsequently carried out to simulate the transportation characteristics for fluid particles. Pollutant trajectory in the MPT model is simulated by tracking a large set of particles. The MPT model is superior to standard single-particle trajectory model because it can better take into account the substantial local variability of the wind field, and hence provides a better

15 description of the overall behavior of the air pollutants. Positions of each particle at time $t+\Delta t$ are represented by discrete element, are computed from the following equation:

$x_{i}(t+\Delta t)=x_{i}(t)+u_{i} \Delta t$

where $i=1,2$ or 3 stands for the $x, y$, and $z$ component. The wind velocity $u_{i}\left(x_{i}, t\right)$ are obtained directly from the meteorological model MM5. The time step $\Delta t=5 \mathrm{~s}$ is chosen to resolve the fine scale flow fields (Fung et al., 2005). Since the grid-scale meteorological variables are defined only on the $1-\mathrm{km}$ MM5 model grid mesh, a linear interpolation scheme (both in time and space) is used to estimate their values at each particle location. Continuous-equal-spacing 4 by 4 emission sources are chosen (see Fig. 1) to release particle tracers, in order to identify the locations of pollution sources

25 over PRD which contribute to the pollution. They are all released with the same emission rate of one particle per ten seconds at two different heights: one is located at $10 \mathrm{~m}$ 
AGL representing ground level emissions; the other is located at $300 \mathrm{~m}$ AGL representing emissions from power plants. A 5-day simulation is conducted by the MPT model and the 24-h MM5 simulated winds are repeatedly used to drive the MPT model during the simulation period. The length of this $24-\mathrm{h}$-effective MM5 simulation is theoretically 5 enough to capture the daily diurnal features of the local atmospheric circulations. The 5 -day period is chosen to see how the impact of those daily diurnal features (we assume they have remarkably similarity from day to day) on air pollutant transport in a long term aspect. To investigate the pollutant transport characteristics over the western and eastern Hong Kong, two sampling zones roughly representing western and to eastern Hong Kong are chosen (see Fig. 1).

\subsection{Emission weighting factors}

In reality, the emission sources are not distributed homogenously across the PRD region. The emission inventories highly dependent on the degree of urbanization, industrial and economic activities, as well as population in the region. Because of the inho-

15 mogenous distribution of the emission sources, constant and uniform emission rates in the MPT model do not represent the actual situation over the PRD. Therefore, several weighting factor of vaious pollutants are introduced to make the simulation more realistic.

First, based on emission database for 2001 provided by the HKEPD, emission weighting factors are assigned for primary pollutants $\left(\mathrm{PM}, \mathrm{SO}_{2}\right.$ and $\left.\mathrm{NO}_{\mathrm{x}}\right)$ at each of the 16 emission sources at two levels $(10 \mathrm{~m}$ representing ground level emissions and $300 \mathrm{~m}$ representing power plant emissions). These weighting factors are listed in Table 2, and 59 power plants are included in this study (Fig. 1).

For PM emission over the PRD, as shown in Table $2 a$, surface emission at 25 Guangzhou (source D) has the highest weighting factor of 26.0, indicating it contributes $26 \%$ to the total PM emission in the study domain. The second largest producer with weighting factor 12.7 is surface emission source at Shenzhen (source J). The streetlevel emission from Hong Kong (sources I and M with weighting factor of 0.57 and 6473

2.01 respectively) are relatively low comparing with the sources outside the territory. The total PM emission from power plants is around one-seventh of the surface emissions. Among the power plant emission, source $\mathrm{H}$, the areas between Guangzhou and Dongguan, is the major contributor with weighting factor 4.38. The mass proportion 5 parameter $M_{P M}=0.15$ stated in Table $2 a$ reflects the fact that the overall emission of $\mathrm{PM}$ in mass contributed $15 \%$ to the emission of total primary pollutant (i.e. sum of PM, $\mathrm{SO}_{2}$ and $\mathrm{NO}_{\mathrm{x}}$ ) in the region.

Most of the emissions of $\mathrm{SO}_{2}(68 \%)$ in the study domain, as summarized in Table $2 \mathrm{~b}$, come of power plants. Major $\mathrm{SO}_{2}$ sources include the emissions from power plants 10 located at Guangzhou (source H,WF=17.09) and Dongguan (source K, WF=14.7), and ground level emissions at Guangzhou (source D, WF=10.54). The three power plants in Hong Kong, Lamma power station (source M), and Castle Peak power station and Black Point power station (source I), with weighting factor 5.9 and 4.74 respectively, contribute around $11 \%$ of total $\mathrm{SO}_{2}$ emission to the region. Sulphur dioxide is the major

15 primary pollution emissions in the region, contributing over half of the pollutant masses among the three primary sources $\left(M_{\mathrm{SO}}=0.53\right)$.

For $\mathrm{NO}_{\mathrm{x}}$ emission which is listed in Table 2c, surface emissions and plant power emissions contribute about the same amount to the region. Major contributor includes emissions from the area sources (source $D, W F=12.37$ ), and power plant emission

20 at Guangzhou (source H, WF=12.14) and Dongguan (source K, WF=12.14). The overall $\mathrm{NO}_{\mathrm{x}}$ emission in mass is $32 \%$ of the total emission of the three primary pollution emissions.

To evaluate the local and regional contribution of primary pollutants to Hong Kong, the amount of tracers from the 16 sources collected in the sampling zones is multiplied 25 by their corresponding weighting factor. For example, the contribution of pollutant $X$ (where $X$ could either be $\mathrm{PM}, \mathrm{SO}_{2}$ or $\mathrm{NO}_{\mathrm{x}}$ ) from emission source $i$ to Hong Kong at time $t$ is calculated by:

$X(i, t)=M_{X} \times W F_{X}(i) \times A T(i, t)$

where $M_{X}$ and $W F_{X}$ are the mass proportion parameter and the weighting factor of the 6474 
source $i$ for a specific pollutant. $A T$ is the amount of tracers collected in the sampling zones (western or eastern Hong Kong) from each source grid. Note that Eq. (2) provides the relative contribution of the 16 sources to Hong Kong pollution instead of the absolute amount of pollutants.

\section{$5 \quad 2.4$ Conversion factors}

Ambient particulate matter consists of both primary and secondary particles (Seinfeld and Pandis, 1998). Primary particles are those directly emitted by sources. These particles undergo few changes between source and receptor, and the atmospheric concentrations are, on average, proportional to the quantities emitted. On the other hand,

10 secondary particles are those formed in the atmosphere from gases which are directly emitted by sources. Sulfate, nitrate, ammonium, and possibly hydrogen ions, are the most common components of secondary particles in the atmosphere. These particles are mainly associated with emissions of $\mathrm{SO}_{2}, \mathrm{NO}_{\mathrm{x}}$, and ammonia $\left(\mathrm{NH}_{3}\right)$ gases.

Yuan et al. (2006a) estimated that secondary aerosol accounted for an annual av-

15 erage of $44 \%$ of $\mathrm{PM}_{10}$ in Hong Kong. Therefore, formation of secondary particles should not be neglected for any PM study in Hong Kong and PRD area. The ambient concentrations of secondary particles are not necessarily proportional to quantities of emissions since the rates at which they form and their gas/particle equilibria may be controlled by factors other than the concentration of the precursor gases. Reactive organic gases are also precursors to secondary particles. On the basis of the past observational records, Yuan et al. (2006b) has derived an empirical relationship between local secondary sulfate and secondary organic carbon (SOC) in Hong Kong, and this relationship could serve as a tool for further secondary organic compound estimation. Since the emission and chemical transformation processes of SOC precursors are 25 much less understood than those for inorganic species, this study limits itself to the inorganic components of secondary aerosol.

In the present study, the ambient RSP level is roughly assumed as the sum of primary particles and two types of secondary inorganic particles, ammoniated sulfate and 6475

ammoniated nitrate. Two parameters, $R_{S}$ and $R_{N}$, are introduced here to account for the fractions of $\mathrm{SO}_{2}$ and $\mathrm{NO}_{\mathrm{x}}$ that are eventually transformed to sulfate and nitrate, respectively. A first-order assumption has been made here that these parameters remain constant for all the source points, regardless of how far the emission sources to the 5 receptor are. Therefore, Eq. (2) could be generalized to the form

$$
\begin{aligned}
& \mathrm{RSP}=\operatorname{PrimaryPM}(\mathrm{PPM})+\text { Sulfate }+ \text { Nitrate } \\
& \operatorname{RSP}(i, t)=\left\{M_{\mathrm{PM}} \times W F_{\mathrm{PM}}(i)+R_{\mathrm{S}} \times M_{\mathrm{SO}} \times W F_{\mathrm{SO}}(i)\right. \\
&\left.+R_{N} \times M_{\mathrm{NO}} \times W F_{\mathrm{NO}}(i)\right\} \times A T(i, t)
\end{aligned}
$$

where

$$
\begin{aligned}
& R_{S}=\left(\frac{\mathrm{SO}_{4}}{\mathrm{PPM}}\right)_{\mathrm{Obs}} \times \frac{\sum_{i} \sum_{t} M_{\mathrm{PM}} \times W F_{\mathrm{PM}}(i) \times A T(i, t)}{\sum_{i} \sum_{t} M_{\mathrm{SO}} \times W F_{\mathrm{SO}}(i) \times A T(i, t)} \\
& R_{N}=\left(\frac{\mathrm{NO}_{3}}{\mathrm{PPM}}\right)_{\mathrm{Obs}} \times \frac{\sum_{i} \sum_{t} M_{\mathrm{PM}} \times W F_{\mathrm{PM}}(i) \times A T(i, t)}{\sum_{i} \sum_{t} M_{\mathrm{NO}} \times W F_{\mathrm{NO}}(i) \times A T(i, t)}
\end{aligned}
$$

Based on the $\mathrm{PM}_{10}$ observations in a 4.5-year period, Yuan et al. (2006a) applied Positive Matrix Factorization model to apportion the ambient PM level in Hong Kong into sources or source categories. This technique could be used for source identification and as a result, sources responsible for primary pollutants as well as secondary sulfate 15 and nitrate could be derived and the values, also shown in Table 3 could serve as inputs to the above equations. The components in Eqs. (4) and (5) include chemical transformation rates $\left(R_{S}\right.$ and $\left.R_{N}\right)$ which are derived from other components in the present study, observational measurements $\left(\mathrm{SO}_{4} / \mathrm{PPM}\right.$ and $\left.\mathrm{NO}_{3} / \mathrm{PPM}\right)$, spatially varied source contribution resulted from emission inventories ( $M$ and $W F$ ), and physical paths 20 of the air masses/pollutants $(A T)$. 


\section{Impact from local and regional sources during calm-weather situations}

Geographically, Hong Kong is a highly urbanized city with mountainous terrain and complex coastlines. With a calm background winds or weak synoptic forcing which is conducive to severe air pollution episodes, thermally induced winds such as LSB 5 circulation and UHI circulation can occur in Hong Kong and PRD. The LSB circulation has been proved as a significant influence on air-flow pattern and affects the air quality, both in Hong Kong (Kok et al., 1997; Fung et al., 2005; Huang et al., 2005; Lam et al., 2006) and in the PRD (Lo, 2006). For this reason, we will first examine the pollutants transport characteristics over PRD under a situation of total stationary meteorological conditions. In this simulation, no horizontal pressure gradient and no background winds are ingested in the MM5 initial and boundary conditions. This case represents an extreme situation of total stationary synoptic weather, and therefore circulations are solely driven by the local thermal effects.

\subsection{Particle-flow patterns}

15 Three plume emitters located at ground level (10 m AGL) at Guangzhou, Shenzhen, and Hong Kong (sources D, J, and M respectively) are selected to demonstrate the pollutants transport characteristics under this stationary meteorological condition. Figure 2 illustrates features of the particle-flow patterns. The positions of particles at selected times are projected onto a horizontal and a vertical plane. These particle-flow

20 patterns are not weighted and it can be regarded as the physical path component $A T$ in Eqs. (4), (5) and (5).

In Fig. 2a, at 15:00 LST of the first day simulation, while the afternoon sea breeze circulation (SBC) is dominant over the PRD, the particles released at Shenzhen and Hong Kong are trapped by the SBC over the Hong Kong territory. From the vertical cross projection (Fig. 2a), the tracers released at $10 \mathrm{~m} \mathrm{AGL}$ can be brought to $2 \mathrm{~km}$ by the SBC. The horizontal extension of the SBC is about 20 to $30 \mathrm{~km}$ and penetrated almost half of the Hong Kong territory. On the third afternoon (Fig. 2b), since there is

$$
6477
$$

no strong synoptic wind to clean the pollutants away from the simulation domain, the situation become much worse. Pollutants released at Guangzhou are transported to Hong Kong and well-mixed with the other two sources within the planetary boundary layer by the SBC.

This result demonstrates that under a calm meteorological condition, air mass/pollutant flow pattern over PRD are substantially modified by the LSB circulation. Pollutants emitted in the PRD can be transported for long distances by the LSB circulation and impact the air quality in Hong Kong. In the afternoon, the SBC can trap the pollutants from local production or from regional transport, and enhance the 10 pollutants accumulation and cross-mixing within the lower part of the atmosphere over the Hong Kong territory.

\subsection{Contribution of the local and regional sources}

By applying Eq. (4), time series of the contribution from ground level and power plant emissions at the 16 sources to total RSP in western and eastern Hong Kong under this calm meteorological condition is shown in Figs. 3 and 4 , respectively.

The RSP in western Hong Kong, as shown in Fig. 3, are mostly contributed by the surface emissions from Guangzhou (source D) in this case. The power plant emissions from local production (source I) and regional transport from Dongguan (source $\mathrm{K}$ ) and Shenzhen (source J) also contribute a large amount of RSP to Hong Kong. The pol20 lution level in Hong Kong is highly correlated with the diurnal cycle of LSB circulation. During the daytime, while SBC is prominent, pollutants emitted from local production (source I) and from the neighboring city Shenzhen (source J) are trapped by the SBC. The SBC not only traps local pollutants, but also transports, accumulates and cross mixes pollutants from the other PRD cities (source $\mathrm{C}, \mathrm{D}, \mathrm{H}$ and $\mathrm{K}$ ), thus causing a late 25 afternoon daily pollution peak around 2000 LST in the western Hong Kong. During the night, emission sources from eastern Pearl River coast (source I, J, and K) generally dispersed away the territory by the land-breeze. However, at the same time, large amount of pollution are being transported from northwestern PRD (source $D$ and $H$ ) to 
western Hong Kong by the large-scale land-breeze over the PRD, partly compensating the dispersion by local land-breeze. In addition, pollutants from the local emission in Kowloon (source M) are transported to the western Hong Kong during the nighttime.

The air quality in the eastern Hong Kong, as shown in Fig. 4, is generally better than

5 that in western side. Table 4 summarizes the pollution level in western and eastern Hong Kong. Under the calm meteorological condition, the amount of RSP in eastern side $(40 \%)$ is $33 \%$ less than the value in western side $(60 \%)$. During the daytime, large amount of pollutants emitted from ground level at eastern Shenzhen (source N) and small amount pollutants from local production (source $\mathrm{M}$ ) are trapped by the SCB.

10 Because the eastern Hong Kong is not directly connected with the Pearl River Estuary (see Fig. 1), where most urban and industrial areas are located along the two sides, regional pollutant transport by the SBC is generally not as serious as that in western side during the afternoon. Instead, pollutants are mainly transported to eastern Hong Kong during the night by the land-breeze, and accumulated in the territory.

15 Table 5 summarizes the proportion of pollutants from local production and regional transport in Hong Kong during the 5-day simulation. Emission sources I and $\mathrm{M}$ are regarded local production while the other emission sources are regarded as regional transport. During the calm meteorological conditions, $78 \%$ of the RSP in Hong Kong are contributed by regional transport while the local production only contributes $22 \%$.

20 The power plants within the PRD contribute 49\%, while the local power plants only contribute $16 \%$ of the RSP total in Hong Kong.

\section{Impact from local and regional sources during typical-wind situations}

Hong Kong is located in the sub-tropical zone; the surface prevailing winds are affected by the northeasterly trade-wind belt most of the time. According to the wind statistics 25 reported by Hong Kong Observatory (Wong and Kwan, 2002), between 1990 and 2000, the probability of prevailing easterly to northeasterly surface winds was about $65 \%$, with an average wind speed of $6 \mathrm{~m} \mathrm{~s}^{-1}$ at Waglan Island, the station generally accepted as

6479

representing background wind data for Hong Kong. Therefore in this simulation, a wind profile with $6 \mathrm{~m} \mathrm{~s}^{-1}$ northeasterly wind at the surface and $6 \mathrm{~m} \mathrm{~s}^{-1}$ westerly wind above the attitude of $1.5 \mathrm{~km} \mathrm{AGL}$, is ingested into the MM5 initial and boundary conditions, in order to examine the pollutants transport characteristics over PRD in a typical-wind 5 situation.

\subsection{Particle-flow patterns}

Figure 5 presents the particle-flow patterns of the three sources (source $\mathrm{D}, \mathrm{J}$ and $\mathrm{M}$ ) under this typical-wind meteorological condition. From the vertical cross section, it can be seen that the structure of the SBC is strongly influenced by the background winds.

10 The SBC cells are not well developed compared to that in calm weather case (Fig. 2) over Hong Kong. However, these $6 \mathrm{~m} \mathrm{~s}^{-1}$ winds could not completely eliminate the afternoon SBC, since a small account of pollutants are still trapped along the Hong Kong coast during the afternoon. The air quality of Hong Kong in this situation is much better than those during calm weather. Most of the pollutants are cleaned away the computational domain by the strong background winds.

\subsection{Contribution of the local and regional sources}

The contribution of the 16 emission sources to total RSP in western Hong Kong during typical wind condition is shown in Fig. 6, while the values in eastern Hong Kong is shown in Fig. 7. Comparing with the case without background winds (Figs. 3 and

204 ), the strong winds generally help to disperse the pollution and reduce the diurnal variation of the emission sources. The level of pollution trapping and accumulation in both western and eastern Hong Kong is substantially reduced. During the daytime, because the strong background winds still cannot destroy the SBC completely, small amount of pollutants are trapped over the Hong Kong coast as evidenced by the daily

25 pollution maximum from source I and $\mathrm{J}$ to western Hong Kong (Fig. 6), and source $\mathrm{N}$ and $\mathrm{M}$ to eastern Hong Kong (Fig. 7). For source N, it is interesting to see that during 
the night, while the sea-breeze diminished, pollutants are no longer trapped in the eastern Hong Kong (Fig. 7, N), but being transported by the background wind toward the western Hong Kong (Fig. 6, N).

In such typical-wind conditions, pollutant trapping and accumulation is not severe 5 over Hong Kong. As summarized in Table 4, the ratio of the total amount of pollutants from the 16 sources accumulated in Hong Kong to that in the calm weather case during the whole 5-day simulation is 0.28 , indicates there is a $72 \%$ difference in the amount of pollutants accumulation in Hong Kong between the two situations. Regional transport contributes $70 \%$ of RSP total in Hong Kong while the local production only contributes 10 $30 \%$, as listed in Table 5 .

\section{Conclusions}

Using the advanced meteorological model MM5 coupled with a three-dimensional multi-particle trajectory model, the pollutant transport characteristics over Hong Kong under two typical meteorological conditions are studied. A conceptual module is used

15 to evaluate the contribution of source regions of RSP. The results indicate that major pollution sources over Hong Kong come from regional transport. In calm-weather days, $78 \%$ of the RSP in Hong Kong are contributed by sources outside Hong Kong, of which surface emissions from Guangzhou are the largest contributor. On the other hand, in normal-day situations with northeasterly surface wind, $71 \%$ of the RSP are contributed

20 by regional transport. Ground level emissions from Shenzhen affect Hong Kong the most in that case.

A physical modeling approach is used to calculate two chemical gas-to-particle conversion rates for $\mathrm{SO}_{2}$ to sulphate $\left(R_{S}=0.29\right)$ and $\mathrm{NO}_{\mathrm{x}}$ to nitrate $\left(R_{N}=0.24\right)$. It should be pointed out that the derivation of these values is subject to the assumption that they remain constant for all the sources and time. In addition, these values tended to be very sensitive to the accuracy of emission data for primary pollutants, based on Eqs. (5) and (6). Nevertheless, although these two parameters are in first-order approximation

$$
6481
$$

in present study, our results demonstrate the importance and usefulness of these two parameters in estimating ambient levels of secondary pollutants in air quality study. For a more accurate investigation, detailed and sophisticated atmospheric chemistry modeling would be required to estimate these two parameters statistically, including 5 their spatial and temporal variations.

The air quality in eastern Hong Kong is comparatively better than the western side. It can be explained that the LSB circulation system in the western Hong Kong are directly connected with the Pearl River Estuary, where most urban and industrial areas are located along the two sides. Pollutants emitted from both sides of the Pearl River Estuary can be transported, cross-mixed and re-circulated over the western Hong Kong, which produced generally worse air quality.

Finally, our analyses clearly shows the significance of regional transport on air pollution in the entire PRD region. Therefore, close collaboration between Hong Kong and Guangdong officials, as well as the public and industries in Hong Kong and the PRD, are very much needed for effective air pollution management in the region.

Acknowledgements. This work was supported by RGC grant NSFC/HKUST36, RGC 402103, UGC under grant no. HIA02/03.SC04, N_HKUST630/04 and NSFC Grant no. 49910161986. The authors want to thank the Hong Kong Environment Protection Department for the provision of air quality data, the Hong Kong Observatory for provision of meteorological data, the Macau

Special Administration Region for provision of meteorological and air quality data.

\section{References}

Chan, C. Y., Chan, L. Y., Zheng, Y. G., Harris, J. M., Oltmans, S. J., and Christopher, S.: Effects of 1997 Indonesian forest fires on tropospheric ozone enhancement, radiative forcing, and temperature change over the Hong Kong region, J. Geophys. Res., 106, 14875-14886, doi:10.1029/2001JD900092, 2001.

Chen, F. and Dudhia, J.: Coupling and advanced land surface-hydrology model with the Penn State-NCAR MM5 modeling system. Part I: Model implementation and sensitivity, Mon. Wea. Rev., 129, 569-585, 2001. 
Dudhia, J.: A nonhydrostatic version of the Penn State-NCAR Mesoscale Model: Validation tests and simulation of an Atlantic cyclone and cold front, Mon. Wea. Rev., 121, 1493-1513, 1993.

Fung, J. C. H., Lau, A. K. H., Lam, J. S. L., and Yuan, Z.: Observational and modeling analysis

5 of a severe air pollution episode in western Hong Kong, J. Geophys. Res., 110, D09105, doi:10.1029/2004JD005105, 2005.

Grell, G. A., Dudhia, J., and Stauffer, D. R.: A description of the fifth generation Penn StateNCAR Mesoscale Model (MM5), NCAR Tech. Note NCAR/TN-398+STR, 138 pp., 1994.

Harris, J. M. and Kahl, J. D. W.: An analysis of 10-day isentropic flow patterns for Barrow, Alaska: 1985-1992, J. Geophys. Res., 99, 25845-25 855, 1994.

HKEPD: Air quality in Hong Kong, Annual Report, Environmental Protection Department, The Government of the Hong Kong Special Administrative Region, 45 pp., 2003.

http://www.epd.gov.hk/epd/english/environmentinhk/air/air_quality/files/aqr03e.pdf, 2003.

Hong, S. Y. and Pan, H. L.: Non-local boundary layer vertical diffusion in a medium range forecast model, Mon. Wea. Rev., 124, 2322-2339, 1996.

Huang, J. P., Fung, J. C. H., Lau, A. K. H., and Qin, Y.: Numerical simulation and process analysis of typhoon-related ozone episodes in Hong Kong, J. Geophys. Res., 110, D05301, doi:10.1029/2004JD004914, 2005.

Kok, G. L., Lind, J. A., and Fang, M.: An airborne study of air quality around the Hong Kong territory, J. Geophys. Res., 102, 19 043-19 057, 1997.

Lam, J. S. L., Lau, A. K. H., and Fung, J. C. H.: Application of refined land-use categories for high resolution meso-scale atmospheric modelling, Bound.-Layer Meteor., 119, 263-288, doi: 10.1007/s10546-005-9027-3, 2006.

Liu, Y., Chen, F., Warner, T., and Basara, J.: Verification of a mesoscale data-assimilation and forecasting system for the Oklahoma City area during the joint urban 2003 field project, J. Appl. Meteorol., in press, 2006, .

Lo, J. C. F.: Implication of urbanization on meteorology and air quality, Ph.D. thesis, 165 pp., The Hong Kong University of Science and Technology, 2006.

Mlawer, E. J., Taubman, S. J., Brown, P. D., lacono, M. J., and Clough, S. A.: Radiative transfer for inhomogeneous atmosphere: RRTM, a validated correlated-k model for the longwave, J. Geophys. Res., 102, 16 663-16 682, 1997.

Oltmans, S. J., Johnson, B. J., Harris, J. M., et al.: Tropospheric ozone over the North Pacific from ozonesonde observations, J. Geophys. Res., 109, D15S01,

6483

doi:10.1029/2003JD003466, 2004.

Seinfeld, J. H. and Pandis, S. N.: Atmospheric chemistry and physics: from air pollution to climate change, John Wiley and Sons, New York, 1998.

Stelson, A. W. and Seinfeld, J. H.: Relative humidity and temperature dependence of the ammonium nitrate dissociation constant, Atmos. Environ., 16, 983-992, 1982.

Wong, M. S. and Kwan, W. K: Wind statistics in Hong Kong in relation to wind power, Hong Kong Observatory Technical Note, No. 77, 2002.

Yuan, Z. B., Yu, J. Z., Lau, A. K. H., Louie, P. K. K., and Fung, J. C. H.: Application of positive matrix factorization in estimating aerosol secondary organic carbon in Hong Kong and its relationship with secondary sulfate, Atmos. Chem. Phys., 6, 25-34, 2006a.

Yuan, Z. B., Lau, A. K. H., Zhang, H. Y., Yu, J. Z., Louie, P. K. K., and Fung, J. C. H.: Identification and spatiotemporal variations of dominant $\mathrm{PM}_{10}$ sources over Hong Kong, Atmos. Environ., 40, 1803-1815, 2006b. 
Table 1. MM5 domain configurations and physics options.

\begin{tabular}{ll}
\hline Domain dimensions & $300 \times 300$ \\
Grid size & $1 \mathrm{~km}$ \\
Vertical layers & 35 (about 12 layers below $1 \mathrm{~km} \mathrm{AGL)}$ \\
Cumulus Scheme & None \\
Moisture scheme & Simple ice scheme \\
PBL scheme & MRF scheme \\
Radiation scheme & RRTM longwave scheme \\
Land surface scheme & Noah LSM \\
\hline
\end{tabular}

6485

Table 2. Weighting factors (WF) of the 16 emission sources for surface and power plants (bracketed values) of (a) PM, (b) $\mathrm{SO}_{2}$, and (c) $\mathrm{NO}_{\mathrm{x}}$ emission.

\begin{tabular}{llllllll} 
(a) & & & & & & \\
\hline Source & WF & Source & WF & Source & WF & Source & WF \\
\hline D & $26.0(0.75)$ & H & $4.00(4.38)$ & L & $1.99(0.21)$ & $\mathrm{P}$ & $1.92(0.02)$ \\
C & $7.60(1.03)$ & G & $4.02(0.10)$ & K & $6.56(1.51)$ & $\mathrm{O}$ & $1.28(0.03)$ \\
B & $6.75(0.59)$ & $\mathrm{F}$ & $1.81(0.00)$ & $\mathrm{J}$ & $12.7(1.65)$ & $\mathrm{N}$ & $6.41(0.13)$ \\
A & $0.99(0.36)$ & $\mathrm{E}$ & $3.01(0.05)$ & $\mathrm{I}$ & $0.57(0.89)$ & $\mathrm{M}$ & $2.01(0.64)$ \\
Total & $87.7(12.3)$ & $\mathrm{M}_{\mathrm{PM}}$ & 0.15 & & & & \\
\hline
\end{tabular}

(b)

\begin{tabular}{llllllll}
\hline Source & WF & Source & WF & Source & WF & Source & WF \\
\hline D & $10.54(4.39)$ & $\mathrm{H}$ & $1.39(17.09)$ & $\mathrm{L}$ & $0.44(0.45)$ & $\mathrm{P}$ & $0.75(0.00)$ \\
$\mathrm{C}$ & $2.53(8.04)$ & $\mathrm{G}$ & $1.19(1.35)$ & $\mathrm{K}$ & $2.26(14.7)$ & $\mathrm{O}$ & $0.28(0.43)$ \\
$\mathrm{B}$ & $2.40(1.94)$ & $\mathrm{F}$ & $0.55(0.00)$ & $\mathrm{J}$ & $5.37(8.44)$ & $\mathrm{N}$ & $2.59(0.39)$ \\
$\mathrm{A}$ & $0.23(0.16)$ & $\mathrm{E}$ & $1.09(0.22)$ & $\mathrm{I}$ & $0.12(5.9)$ & $\mathrm{M}$ & $0.03(4.74)$ \\
Total & $31.8(68.2)$ & $\mathrm{M}_{\text {SO }}$ & 0.53 & & & & \\
\hline
\end{tabular}

(c)

\begin{tabular}{llllllll}
\hline Source & WF & Source & WF & Source & WF & Source & WF \\
\hline D & $12.37(2.56)$ & $\mathrm{H}$ & $2.63(12.14)$ & $\mathrm{L}$ & $1.25(0.41)$ & $\mathrm{P}$ & $0.57(0.02)$ \\
$\mathrm{C}$ & $3.78(6.42)$ & $\mathrm{G}$ & $1.86(0.97)$ & $\mathrm{K}$ & $3.5(12.37)$ & $\mathrm{O}$ & $0.87(0.11)$ \\
$\mathrm{B}$ & $2.47(1.39)$ & $\mathrm{F}$ & $0.74(0.00)$ & $\mathrm{J}$ & $7.53(4.07)$ & $\mathrm{N}$ & $4.25(0.33)$ \\
$\mathrm{A}$ & $0.68(0.12)$ & $\mathrm{E}$ & $1.91(0.19)$ & $\mathrm{I}$ & $1.25(5.65)$ & $\mathrm{M}$ & $4.58(2.98)$ \\
Total & $50.3(49.7)$ & $\mathrm{M}_{\text {NO }}$ & 0.32 & & & & \\
\hline
\end{tabular}


Table 3. The relative amount of ambient measured $\mathrm{SO}_{4}$ and $\mathrm{NO}_{3}$ to PPM and their derived gas-to-particle conversion rates .

\begin{tabular}{ll}
\hline Measurements & Conversion Rates \\
\hline $\mathrm{SO}_{4} / \mathrm{PPM}=0.96$ & $\mathrm{R}_{S}=0.29$ \\
$\mathrm{NO}_{3} / \mathrm{PPM}=0.45$ & $\mathrm{R}_{N}=0.24$
\end{tabular}

6487

Table 4. Relative pollution level and fractions of RSP totals in both western and eastern Hong Kong under two distinct meteorological conditions.

\begin{tabular}{llll}
\hline Synoptic Conditions & Western HK & Eastern HK & Pollution Level \\
\hline Calm-weather & $60.4 \%$ & $39.6 \%$ & 1 \\
Typical-wind & $75.3 \%$ & $24.7 \%$ & 0.28 \\
\hline
\end{tabular}


Table 5. Contribution of local and regional pollution sources to RSP in Hong Kong during (a) calm-weather and (b) typical-wind meteorological conditions.

(a)

\begin{tabular}{llll}
\hline Calm-weather & Surface emissions & Power plant emissions & Total \\
\hline Regional transport & $45.6 \%$ & $32.5 \%$ & $78.1 \%$ \\
Local production & $5.6 \%$ & $16.3 \%$ & $21.9 \%$ \\
Total & $51.2 \%$ & $48.8 \%$ & $100 \%$ \\
\hline
\end{tabular}

(b)

\begin{tabular}{llll}
\hline Typical-wind & Surface emissions & Power plant emissions & Total \\
\hline Regional transport & $44.4 \%$ & $26.2 \%$ & $70.6 \%$ \\
Local production & $11.0 \%$ & $18.4 \%$ & $29.4 \%$ \\
Total & $55.4 \%$ & $44.6 \%$ & $100 \%$ \\
\hline
\end{tabular}

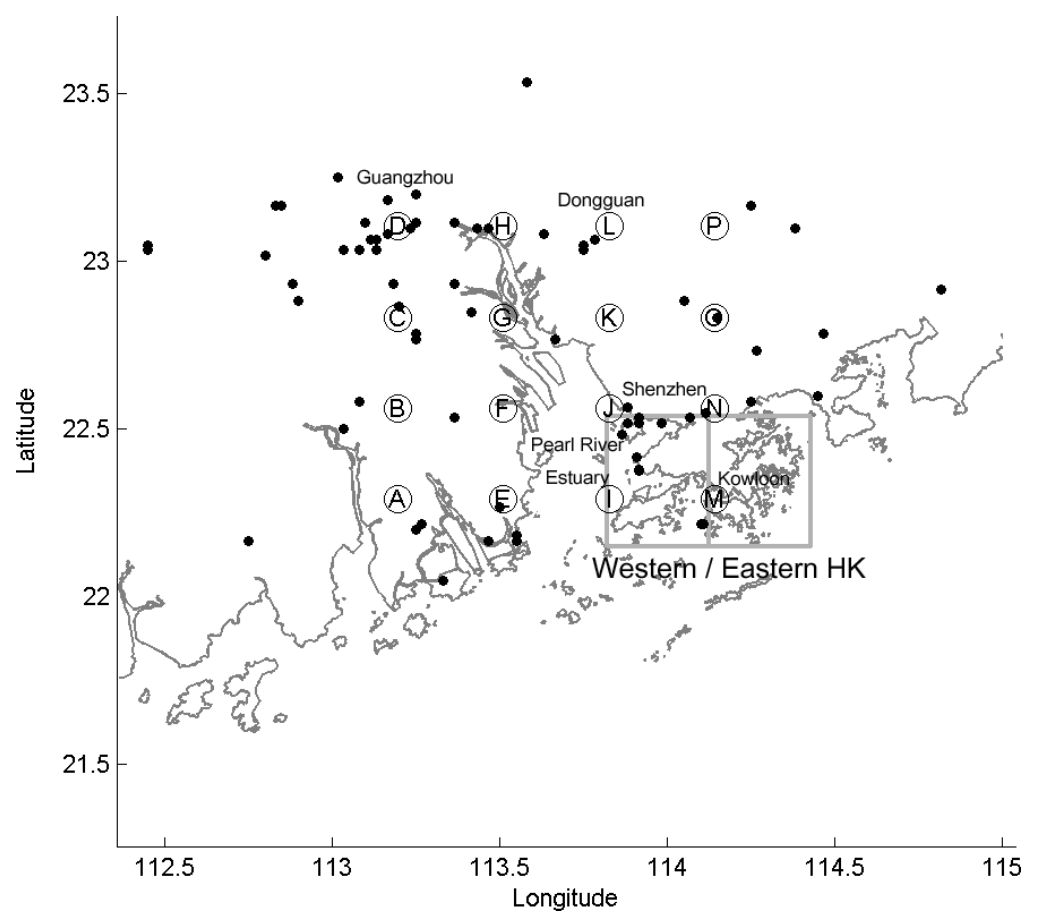

Fig. 1. Map showing the $1-\mathrm{km}$ MM5 domain, locations of the $4 \times 4$ emission sources (A-P), and extensions of the two sampling zones in Hong Kong (grey boxes). Black dots indicate the locations of power plants. 

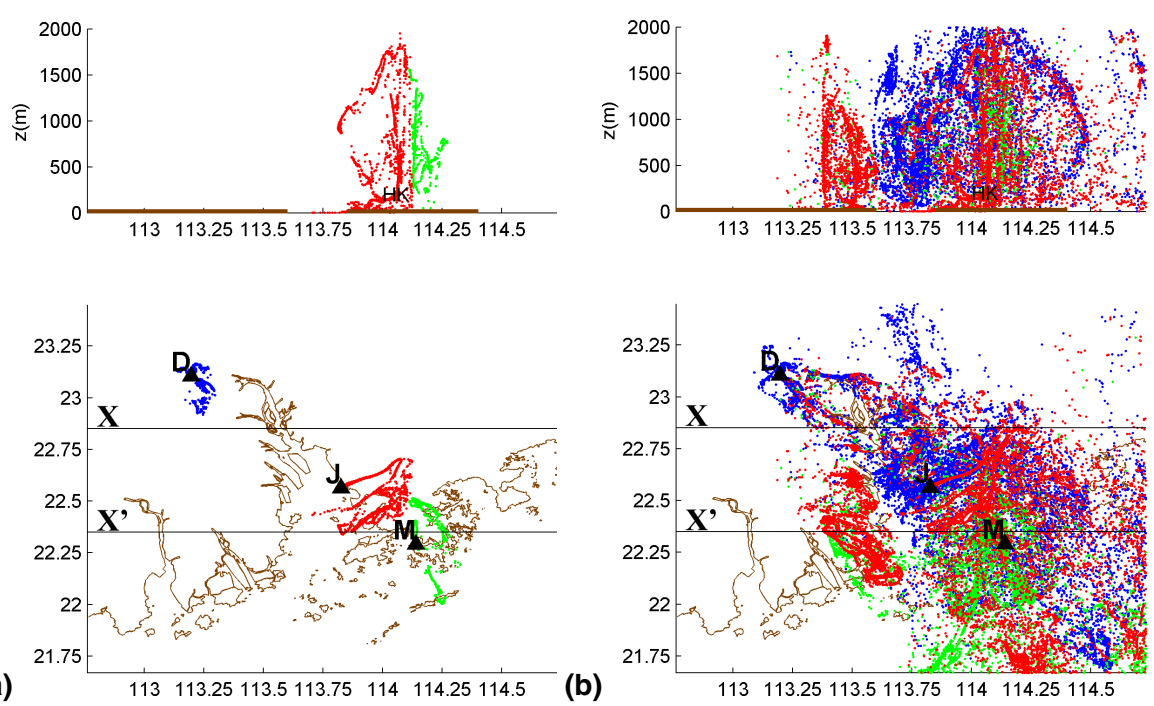

Fig. 2. Particle-flow patterns at 1500 LST for (a) the first and (b) third days of the calm-weather simulations. Triangles $(\boldsymbol{\Delta})$ show the location of three emissions sources located $10 \mathrm{~m}$ AGL. Blue particles were released from Guangzhou (D); red particles were released from Shenzhen $(J)$; green particles were released from Hong Kong (M). The bottom two panels show the horizontal projection. The top two panels show the horizontally integrated vertical cross section of the air column between boundaries $\mathrm{X}$ and $\mathrm{X}^{\prime}$.

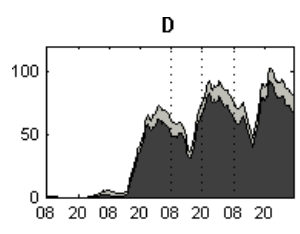

C
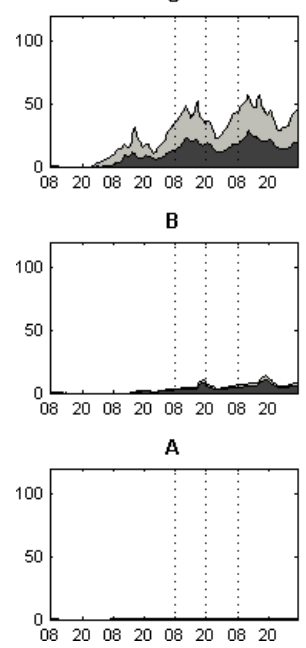

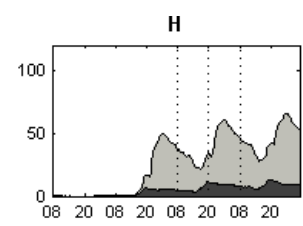

G

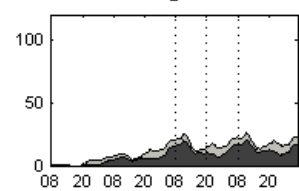

F

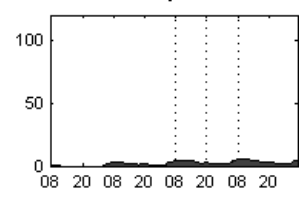

E

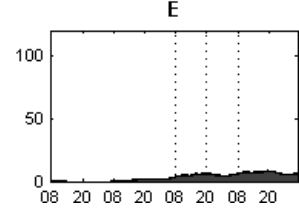

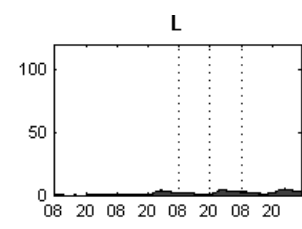

K

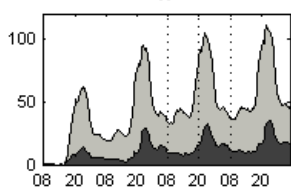

$\mathbf{J}$

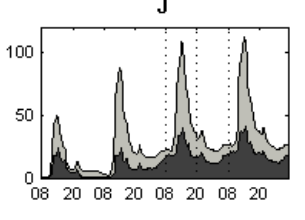

I

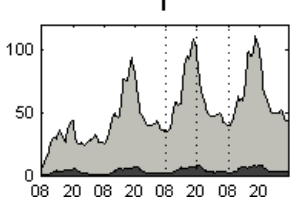

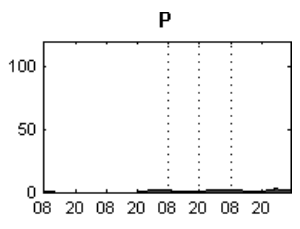

0

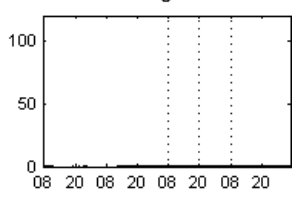

N



M

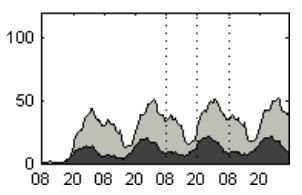

Fig. 3. Time series of the contribution of surface emissions (dark grey) and power plant emissions (light grey) from the 16 sources to total RSP in the western Hong Kong during calmweather days. The title of each plot denotes the emission sources. $x$-axis is time (LST). $y$-axis is the relative amount of RSP within the lower part of PBL (below $1 \mathrm{~km} \mathrm{MSL).}$ 

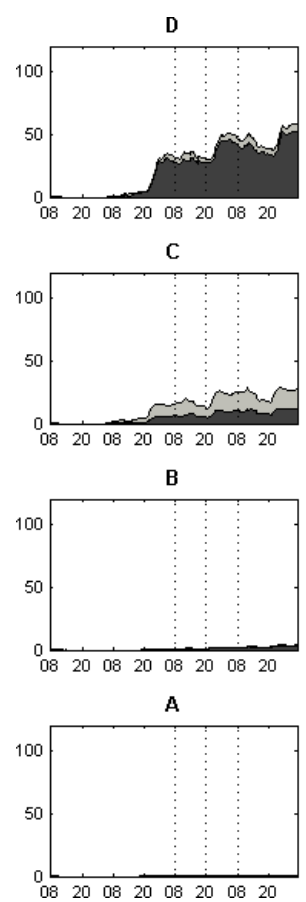

H
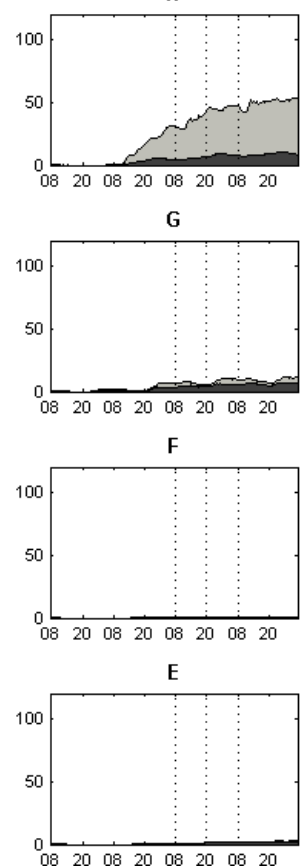

L

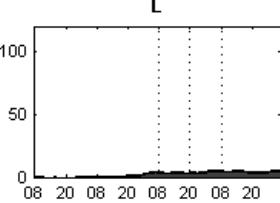

K

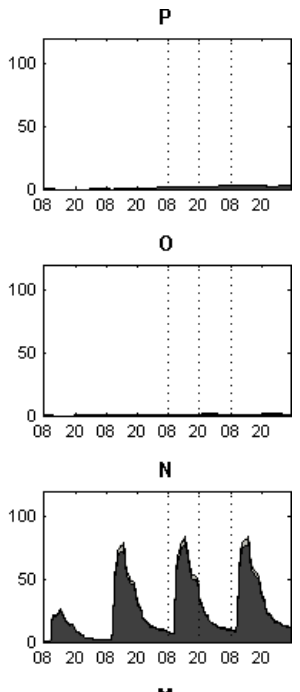

$M$

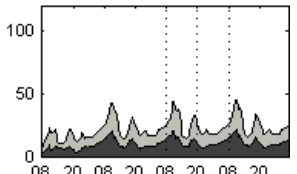

Fig. 4. Same as Fig. 3, but for eastern Hong Kong.
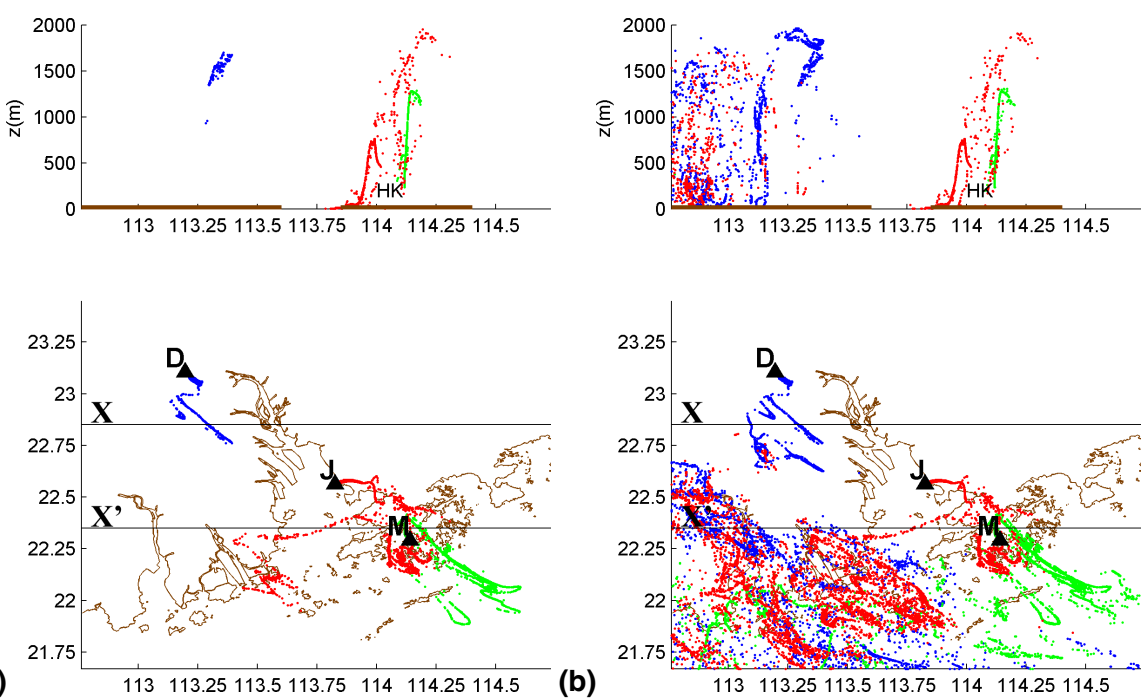

(a)

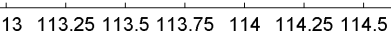

(b)

Fig. 5. Same as Fig. 2, but for typical-wind situations. 

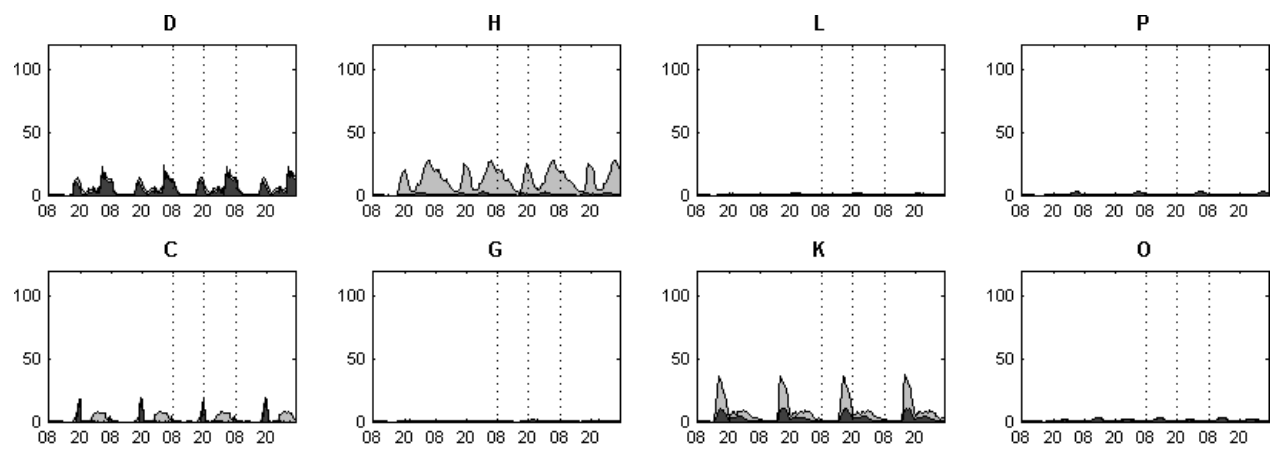

K
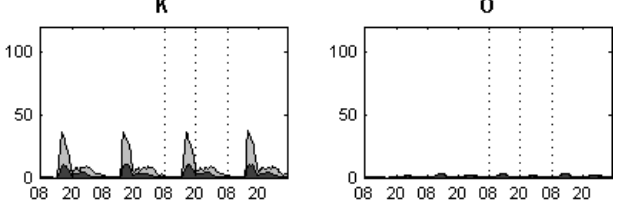

N
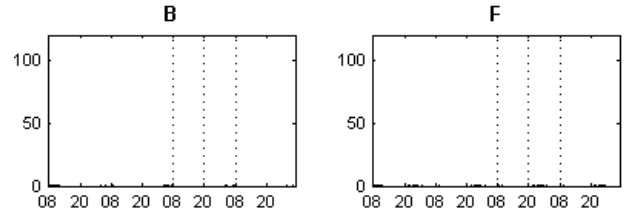

$\mathrm{J}$

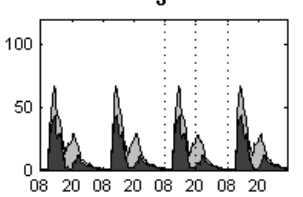

I
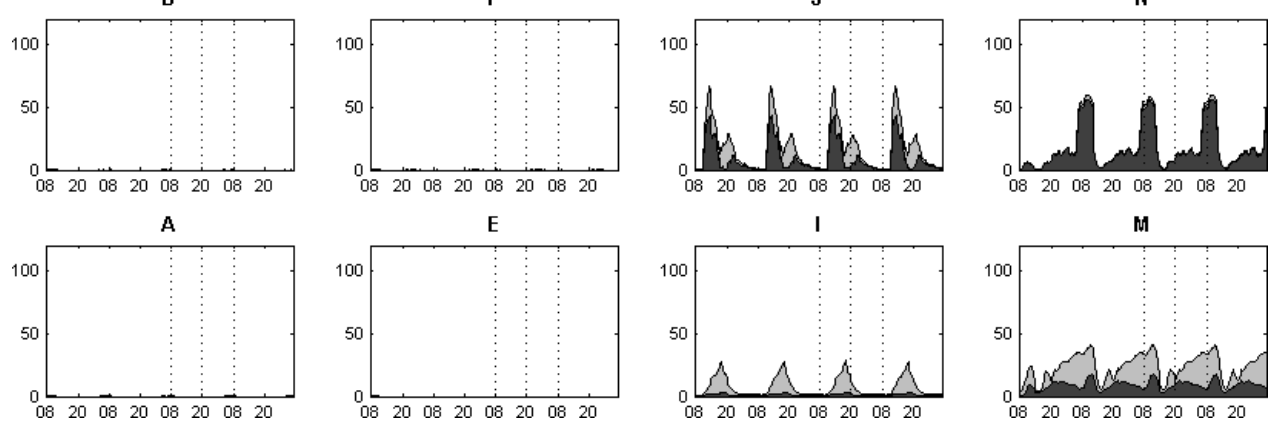

Fig. 6. Same as Fig. 3, but for typical-wind situations.

D

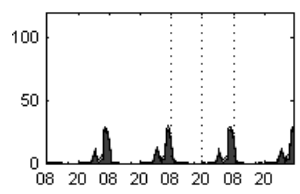

C

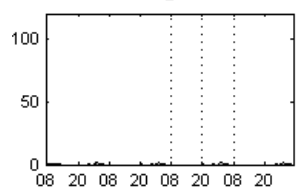

B

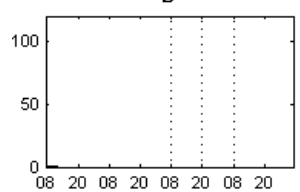

A

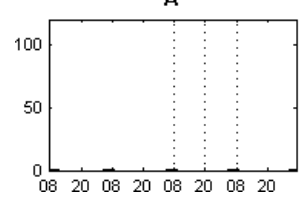

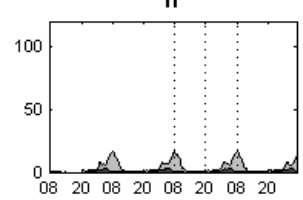

G

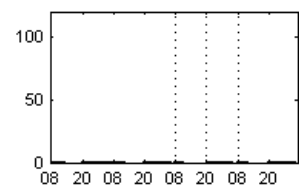

$\mathrm{F}$

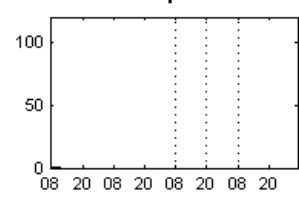

$\mathrm{E}$

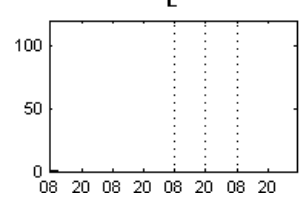

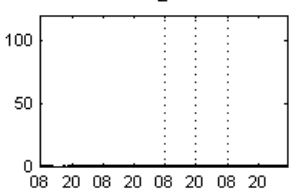

K

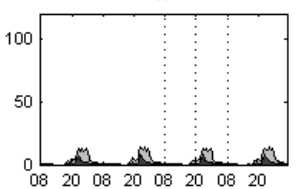

J

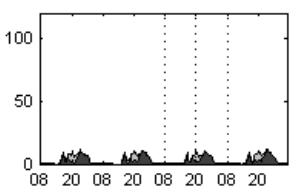

I

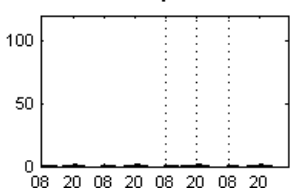

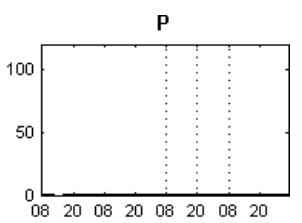

0

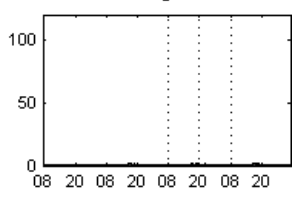

N

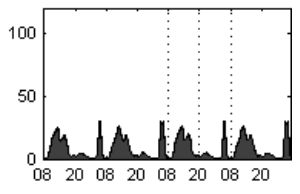

M



Fig. 7. Same as Fig. 4, but for eastern Hong Kong during typical-wind situations. 